\title{
Pendidikan Perilaku Religius Penghuni Rumah Susun Kota Pasuruan Dalam Menciptakan Baiti Jannati
}

\author{
Dewi Masitah \\ Sekolah Tinggi Agama Islam Al-Yasini Pasuruan Jawa Timur \\ Email: masitahdewi2710@gmail.com
}

\begin{abstract}
The Pasuruan city government has built flats in three sub-districts. The apartment in the city of Pasuruan is expected to be a home that protects their family with limited facilities but full of comfort with the aspiration to form a sakinah mawaddah wa rahma family as well as my home to be my paradise. Likewise with an Islamic environment, ethical and interacting with harmonious neighbors. These flats are expected to be their intermediary in achieving their welfare. Building a household in a household with the concept of my home is my heaven (baiti Jannati) in an apartment is very difficult because of the large number of residents and the concept of apartment building is so complex, except with hard effort. of the residents of the apartment. Therefore, special assistance is needed from tertiary institutions based on pesantren to create education and religious behavior for the residents of the apartment so that baiti jannati will automatically be created by itself. This mentoring uses the $A B C D$ mentoring method involving the residents of the flats themselves. The results of our assistance in these flats include the formation of religious families, polite and able to interact with the community in safe harmony and preserving congregational prayers, Islamic studies, jamiyah tahlil, dibaan and TPQ for children.
\end{abstract}

Keywords: Religious Behavior, Apartment Inmates, Baiti Jannati

\section{Pendahuluan}

Rumah merupakan kebutuhan mendasar untuk berlindung, untuk bernaung, tempat membagi kasih sayang keluarga. Rumah adalah bagian terkecil dari sekumpulan komunitas guna berinteraksi denga rumah tangga lainnya dalam bentuk tetangga dan lingkungan yang lebih besar. Semakin banyak penduduk semakin banyak rumah. Banyak pula penduduk yang tidak memiliki rumah karena tidak mampu membelinya. Maka dari permasalahan 
tersebut Pemerintah Kota Pasuruan menjawab permasalahan kemiskinan, padatnya penduduk yang kumuh dan efisiensi tanah serta penataan permukiman masyarakat di perkotaan Pasuruan membangun Rumah Susun Sederhana Sewa (Rusunawa). Keberadaan rusunawa di Kota Pasuruan menjadi amanah Undang-Undang Nomor 20 Tahun 2011 tentang Rumah Susun, yang memiliki rasa keberpihakan pada Masyarakat miskin dan berpenghasilan Rendah (MBR) ${ }^{1}$. Di kota Pasuruan terdapat tiga Rusunawa yang ditempatkan pertama; di kelurahan Tambaan, kecamatan Panggungrejo. Kedua kelurahan Petahunan kecamatan Gadingrejo.

Kedua rumah susun ini masing-masing terdapat 2 gedung dan setiap gedung terdapat 5 lantai dengan jumlah 195 kamar. Pembayaran sewanya bervariasi per bulannya, untuk lantai 1 jumlah kamarnya 4 (empat), untuk sewa per kamar Rp. 110.000, lantai 2 jumlah kamarnya 48, untuk sewa per kamar Rp. 100.000, lantai 3 jumlah kamarnya 48 untuk sewa per kamar Rp. 90.000, lantai 4 jumlah kamar 48 untuk sewa per kamar Rp. 80.000, lantai 5 jumlah kamarnya 48, untuk sewa per kamar Rp.70.000. Masing- masing kamar bertipe 24 yang didalamnya ada ruang tamu, satu kamar, dapur, kamar mandi dan tempat jemuran. Tiap kamar tersebut dilengkapi dengan listrik dan air². Rusunawa ke tiga bertempat di kelurahan Tembokrejo kecamatan Purworejo terdapat satu gedung rusunawa 5 lantai dengan jumlah kamar tipe 36 sebanyak 98 dengan fasilitas didalamnya ada ruang tamu plus kursinya, kamar plus tempat tidur dan almari, dapur serta tempat cucian. Rusunawa ketiga ini sangat berbeda dari kedua rusunawa sebelumnya karna diperuntukkan bagi masyarakat yang berpengahasilan sedang. Syarat untuk menempati rusunawa semuanya sama yakni surat permohonan dapat kamar, surat keterangan kerja dan belum memiliki

\footnotetext{
${ }^{1}$ Hasil wawancara dengan Mokh Su'udi, kepala UPTD Rusunawa di Petahunan pada hari 6 Februari 2018.

${ }^{2}$ Hasil wawancara dengan ibu Marsiyah, Bu RW Rusunawa Tambaan dan Bu Fatimah RT Rusun Petahunan 12 Februari 2018.
}

Pendidikan Perilaku Religius Penghuni Rumah Susun Kota Pasuruan 
rumah, slip gaji, foto copi KTP, KK, dan buku nikah ${ }^{3}$.

Rumah Susun di Kota Pasuruan diharapkan akan menjadi sebagai rumah yang mengayomi keluarga mereka dengan fasilitas terbatas tapi penuh kenyamanan dengan cita-cita membentuk keluarga sakinah mawaddah wa rahma sekaligus rumahku surgaku. Begitu juga dengan lingkungan yang Islami, beretika dan berinteraksi dengan tetangga yang rukun. Rumah susun ini diharapkan sebagai pelantara mereka dalam mencapai kesejahteraan hidup mereka sehingga suatu hari mereka mempunyai rumah yang layak dan mampu meninggalkan rumah susun tersebut dengan baik, sehingga dengan giliranya masyarakat yang membutuhkan tempat tinggal dapat menempatinya. Selain hal tersebut rumah susun diharapkan sebagai wadah komunitas yang bisa dibina dan didampini secara moral Islami sehingga membentuk masyarakat kota Pasuruan yang religius dan mempunyai modal sosial yang bagus.

Kebijakan dan keberpihakan pemerintah kota Pasuruan sebagai kota santri dalam menyediakan rusunawa akan berkualitas ketika tidak hanya menyediakan fasilitas rumah susun saja tapi bagaimana menciptakan lingkungan yang Islami dan rumahku surgaku "bayti jannati". Artinya penghuni rusunawa merasakan ketenangan dalam rumah tangga, kesejateraan, dan damai dengan tetangga sesama penghuni rusun. Menciptakan bayti jannati tidaklah muda, disitu diperlukan usaha dari penghuni rusun sendiri yakni dimulai dari prilaku religius baik dengan keluarganya maupun tetangganya yang sangat variatif karakternya. Guna mempermudah terciptanya suasana bayti jannati di rumah susun tersebut, perlu sekali dilakukan pendampaingan dan pemberdayaan masyarakat. Oleh sebab itu kami selaku akademisi dari perguruan tinggi yan berbasis pesantren Al-Yasini, melakukan pendamingan dengan berikut laporannya.

${ }^{3}$ Hasil observasi di Rusunwa tembok pada tanggal 10 Februari 2018. 
Bayti Jannati berasal dari bahasa Arab bayt yang artinya tempat untuk melewati malam, atau tinggal disiang hari. Kata lainnya adalah dar atau dara berarti mengelilingi, melaksanakan atau melangsungkan ${ }^{4}$. Rumah adalah tempat istirahat, menenagkan jiwa dan raga serta menjadi tempat privasi yang terdapat perlindungan dan keamanan didalamnya ${ }^{5}$.

Rumah merupakan bagian terkecil yang tercipta dari komunitas lingkungan artinya tidak terpisah dari lingkungan sehingga lingkungan ini harus dijaga agar mempunyai hubungan yang harmonis. Keharmonisan hanya bisa tercipta oleh manusia karna manusia bagian dari lingkungan dan yang menjalani kehidupan6. Maka dari hal tersebut jika manusia menginginkan rumah harus memperhatikan lingkungannya terlebih dahulu. Rumah dengan tetangga yang baik, nyaman, dekat masjid atau mushollah untuk menunaikan sholat berjamaah dan membiasakan anak dengan suasana ibadah. Kondisi Islami seperti ini disebut Bayti Jannati.

Ciri bayti jannati adalah rumah yang didalamnya selalu didirikan ibadah kepada Allah, ada internalisasi ajaran dan nilai-nilai Islam secara kaffah (sempurna), ada keteladanan yang baik dari orang tua ke anak. Rumah yang didalamnya ditegakkan syariah, saling bersilaturrahmi dan berinteraksi namun tetap menjaga privasi masing-masing orang7 ${ }^{7}$ Hal terpenting rumah Islami tidak menutup diri dari dunia luar, memungkinkan interaksi, dan hubungan sosial dengan lingkunngan sekitar dan para tetangga bisa berlangsung dengan baik dan rukun, serta tidak menonjolkan kemewahan dan kekayaan. Dalam hal ini jika bertempat tinggal di rumah susun jelas tidak bisa memilih tetangga dahulu dengan keterbatasan ekonomi dan memang sudah didesain demikian oleh pemerintah kota Pasuruan. Selain itu untuk bisa menempati rumah susun harus mengantri. Saat ini sudah terdata

\footnotetext{
${ }^{4}$ Omer, Spahic.2009. dalam Junara dan Putrie. Malaysia.

${ }^{5}$ Omer, Spahic.2009. Islamic Built Environtment.Malaysia.h.163

6 Rehman,A. 2002. The Grand Tradition of Islamic Architecture.London:Routledge Curzon.

${ }^{7}$ Ibid.
}

Pendidikan Perilaku Religius Penghuni Rumah Susun Kota Pasuruan 
sebanyak 300 KK yang antri hendak menempati rumah susun tersebut ${ }^{8}$. Maka warga rusun yang harus berupaya menciptakan suasana lingkungan tersebut dengan rukun dan Islami. Sebuah cara menciptakan bayti jannati yang relevan untuk rumah susun adalah memperhatikan adab dan aturan yang musti diterapkan oleh keluarga muslim rusunawa. Adapun aturanaturan Islami dalam penataan rumah tangga adalah sebagai berikut:

1. Menjaga kebersihan dan kesucian

Penghuni rumah susun harus memperhatikan kebersihan dan kesucian rumahnya dan lingkungannya. Kesucian atau Thaharah, biasanya selalu dihubungkan dengan air, sehingga orang sering mengidentikkan antara kesucian dan kebersihan. Seorang muslim akan sangat memperhatikan kedua masalah tersebut, yaitu kesucian dan kebersihan, dalam waktu yang sama. Seorang muslim, sekaligus akan membersihkan kotoran dan mensucikan najis, menghilangkan sekaligus dua unsur, unsur lahiriah, yaitu kotoran dan unsur ma'nawiyah, yaitu najis ${ }^{9}$. Dalam usaha mewujudkan kebersihan, hendaklah penghuni rusun memperhatikan hal-hal sebagai berikut:

a. Hendaklah penghuni rusun dan anggota keluarganya, membiasakan untuk tidak membuang sesuatu, atau sampah, kecuali pada tempat yang sudah disediakan.

b. Hendaklah kaum wanita penghuni rusun mengatur waku tertentu untuk mencuci pakaian dan perabotan bekas makan.

c. Hendaklah anggota keluarga penghuni rusun memperhatikan barang-barang yang sering terkena debu, kemudian membersihkannya.

d. Hendaklah ada waktu tertentu yang telah disepakati untuk membersihkan rumah.

${ }^{8}$ Hasil wawancara dengan ibu RW di rusun Petahunan pada 18 Februari 2018 jam 10.00 .

${ }^{9}$ Sa'id, Syaikh.2002.Tatanan Rumah Islami. Robbani Press: Bandung.

Pendidikan Perilaku Religius Penghuni Rumah Susun Kota Pasuruan Dalam Menciptakan Baiti Jannati 
e. Hendaklah setiap anggota keluarga penghuni rusun mempunyai jadwal mandi tersendiri, jangan sampai selama satu minggu tidak pernah mandi. Diantara sunnah Rasulullah SAW adalah mandi dihari Jum'at, menggunakan siwak untuk membersihkan gigi, dan menyehatkan gusi.

f. Hendaklah penghuni rumah menata rumahnya, sehingga terbebas dari polusi udara yang tidak sedap, yang membahayakan penghuni rumah, atau tetangganya. Yang paling penting untuk diperhatikan adalah kebersihan dapur, kamar mandi dan WC .

2. Merendahkan suara, menjaga rahasia dan tidak membuat kegaduhan

Dimanapun suatu keluarga hidup, dia akan mempunyai tetangga, rekan sepergaulan, dan kerabat yang hidup disekitarnya, satu atau lebih. Terlebih di rumah susun yang banyak tetangganya atas bawah perlantai. Dari sinilah ditekankan bagi penghuni rumah susun untuk memperhatikan hak-hak mereka, yaitu tidak saling mengganggu satu dengan lainnya. Adapun kegaduhan yang paling mengganggu di dalam rumah, adalah suara yang keras.

Rumah yang lslami, penghuninya tidak akan mendengar hal-hal yang menyakitkan, menyinggung perasaan, atau sesuatu yang mengacaukan suasana dan membuat gaduh. Begitu pula tetangganya akan merasa aman, tidak terganggu oleh kegaduhan dan tidak pernah mendengar hal-hal seperti diatas ${ }^{10}$. Memperhatikan hal diatas, hendaklah keluarga muslim rumah susun memperhatikan hal-hal sebagai berikut:

a. Apabila seorang wanita mempunyai keperluan terhadap anggota keluarganya yang lelaki, sedangkan mereka menghadapi tamu, hendaklah dia mengetuk pintu sebagai pengganti dari panggilan.

10 Ibid. 
b. Jika pintu rumah susun diketuk orang, dan di rumah tersebut ada lelaki, maka merekalah yang harus menjawab ketukan pintu tersebut, jika tidak ada lelaki maka wanita dibolehkan menjawab ketukan itu dengan jawaban yang pendek serta dengan suara yang tegas, suara yang tidak menampakkan kegemulaiannya.

c. Apabila berbincang-bincang baik antara orang tua, atau antara anakanak, atau antara anak dan orang dewasa, hendaklah dengan suara yang wajar. Dan hal yang mesti diperhatikan oleh anggota keluarga adalah hendaklah mereka membiasakan berkata dengan bahasa yang halus.

d. Hendaklah, anggota keluarga rumah susun menjauhkan hal-hal yang akan menimbulkan kegaduhan, suara yang keras, atau sesuatu yang akan menyakiti.

e. Jika dimungkinkan, tidak menggunakan alat yang membuat berisik, dalam memenuhi kebutuhan rumah tangga.

f. Jangan bersikap tidak peduli terhadap anak jika mereka menangis.

g. Hal yang perlu dibiasakan oleh anggota keluarga muslim rumah susun adalah menjaga rahasia. Tidak semua hal yang terjadi dalam rumah mesti diceritakan oleh anggota keluarga. Hal yang paling ditekankan oleh Rasulullah SAW dalam masalah ini, adalah tidak bolehnya suami isteri menceritakan kepada orang lain, hal-hal khusus yang terjadi antara mereka berdua.

3. Tentang tatacara mengatur hal-hal yang berkaitan dengan ilmu dan ibadah

Tidak ada yang lebih penting dalam kehidupan keluarga muslim selain dari dua permasalahan ini, yaitu mengatur hal-hal yang berkaitan dengan ilmu dan ibadah. Hal yang harus menjadi perhatian utama 
dalam masalah ilmu adalah ilmu-ilmu yang wajib dan yang dibutuhkan. ${ }^{11}$

4. Bersikap sederhana dalam makan, minum, berpakain dan gaya hidup Seorang muslim dalam makan dan minumnya dituntut untuk melaksanakan aturan yang telah Allah SWT tentukan:

a. Tidak boleh berlebih-lebihan;

b. Tidak boleh makan dan minum sesuatu yang membahayakan dirinya, apalagi yang haram.

Menumpuk-numpuk pakaian dan barang-barang yang tidak penting pemakaiannya adalah merupakan pemborosan, serta berdampak negatif bagi jiwa. Pakaian mesti disesuaikan dengan kebutuhan kita, begitu pula barang-barang keperluan rumah.Hidup sederhana dan hemat tidak sama dengan sifat kikir. Seorang muslim dilarang bersifat kikir, dan kita tidak bisa memungkiri bahwa kebutuhan keluarga satu sama lainnya saling berbeda, begitu pula zaman pun menuntut perbedaan tersebut. ${ }^{12}$

5. Menjalin hubungan yang baik dan adab bergaul

Keluarga termasuk di rumah susun, lingkungan dan sekolah, adalah sumber pendidikan yang asasi dalam kehidupan manusia. Pengaruh keluarga terhadap seseorang sangat besar. Pada umumnya keluarga akan mempengaruhi seseorang dalam hal agama, akhlak dan adab pergaulannya. Oleh sebab itu, merupakan hal yang penting sekali jika rumah yang islami berperan dalam membentuk seseorang, menyangkut adab bergaulnya dan cara berhubungan dengan masyarakat, sehingga dapat dipraktekkannya di dalam dan diluar rumah. Tolak ukur berbuat baik adalah baiknya hubungan seseorang dengan orang yang paling dekat. Orang terbaik diantara kalian adalah

11Sa'id, Syaikh.2002.Tatanan Rumah Islami. Robbani Press:Bandung.

12 ibid 
yang paling baik kepada keluarganya. Dalam salah satu hadits, Rasulullah SAW bersabda, "Ibumu, ibumu, ibumu kemudian ayahmu, kemudian yang dibawahmu" (HR Bukhari dan Muslim).

Oleh sebab itu di dalam rumah islami termasuk rumah susun harus diterapkan adab pergaulan dan hubungan yang baik. Adab terhadap orang tua adalah dengan menghormatinya, taat kepada keduanya, berbuat baik dan mengistimewakan keduanya. Hal ini harus benar-benar diperhatikan dan dijaga..

Hubungan yang harmonis antara suami dan isteri, bermuamalah dengan penuh kelembutan tidak disertai kekasaran, tidak berteriakteriak, menjauhkan diri dari pertentangan dan perselisihan, isteri taat pada suaminya, memperhatikan dan menjaga anak-anaknya dengan penuh kasih sayang dan keceriaan, mendidiknya dengan baik dalam masalah yang berhubungan dengan agama maupun dunia, semuanya adalah hal-hal yang teramat penting untuk diperhatikan.

6. Memperhatikan kesehatan dan olahraga

Keluarga, lingkungan dan sekolah, adalah sumber pendidikan yang asasi dalam kehidupan manusia. Pengaruh keluarga terhadap seseorang sangat besar. Pada umumnya keluarga akan mempengaruhi seseorang dalam hal agama, akhlak dan, adab pergaulannya. Islam sangat memperhatikan masalah kekuatan, apalagi masalah kesehatan. Oleh sebab itu memperhatikan masalah olahraga dan kesehatan merupakan bagian dari pembinaan rumah lslami, dan merupakan aturan yang mesti dilakanakan dalam rumah.

Setiap anggota keluarga di rumah susun diharapkan membiasakan berolahraga sehingga tiada satu hari pun berlalu tanpa olahraga, apapun bentuknya, jalan kaki, jogging, lari ditempat, senam, lompat tali, dan seterusnya. Pada intinya setiap anggota keluarga rumah susun mesti punya waktu untuk berolahraga. Alangkah baiknya jika 
program olahraga tersebut selalu dipadukan dengan dzikir dan do'a di area rumah susun.

7. Melindungi rumah dan anggota keluarga dari akhlaq, dan perilaku menyimpang, serta menjauhkan mereka dari hal-hal yang haram, makruh, dan membahayakan.

Allah SWT berfirman, "Hai orang-orang yang beriman, peliharalah dirimu dan keluargamu dari api neraka"13. Seorang muslim selalu aktif melaksanakan tuntutan-tuntutan agama, begitu pula terhadap keluarganya dan berusaha untuk menjauhkan dirinya dan keluarganya dari hal-hal yang dilarang oleh agama. Harus menjauhi hal-hal yang bertentangan etika dan akhlaq, apalagi hal-hal yang bertentangan dengan amalan-amalan sunnah, wajib, dan fardhu. Harus diusahakan jangan sampai terjatuh ke dalam hal-hal yang makruh dan haram sudah terbiasa memandang apa yang ada di dalam rumah sebagai aurat yang harus dijaga dari pandangan orang lain. Diantara mereka ada yang selalu menjaga agar orang luar tidak melihat apa yang ada di dalam rumahnya, dan selalu berhati-hati dalam keluar untuk melakukan pekeriaan rumah tangganya, seperti menjemur pakaian atau mengambil jemuran.

Hal yang harus dijaga dalam keluarga yang islami adalah menjaga aurat, jangan sampai menampakkan aurat di hadapan orang lain sekalipun anak kecil. Bahkan semenjak usia dini hendaklah anak-anak dibiasakan untuk menutup auratnya. Hal yang mesti ditanamkan semenjak kecil terhadap anak perempuan adalah jangan menampakkan diri di hadapan laki-laki.

Hal yang perlu dihindarkan dari dalam rumah adalah gambargambar hewan dan patung-patung, serta semua hal yang dimakruhkan

${ }^{13}$ QS. At-Tahriim:6 
dan diharamkan oleh para ulama, walaupun dalam hal ini terdapat perbedaan pendapat. Hal lain yang perlu dihindarkan dari rumah lslami adalah, apa-apa yang termasuk dalam kategori makruh dan haram, seperti kebanyakan acara-acara radio dan televisi, atau pemutaran video dan tape dengan memutar kaset-kaset yang tidak berfaedah .

Hal yang penting untuk diperhatikan dalam rumah lslami ialah membedakan antara dua status kemahraman wanita, yaitu antara wanita yang haram dinikahi untuk selamanya dan wanita yang haram dinikahi hanya untuk sementara. Terhadap wanita yang bukan mahram dilarang menjabat tangannya, menyentuhnya, berduaan dengannya, membuka aurat, dan bersolek dihadapannya. Sungguh ada sebagian lingkungan yang menyepelekan masalah ini. Kepada mereka harus dikenalkan hukum-hukum syari"ah dan ditekankan agar senantiasa terikat dengan hukum tersebut .

8. Berbuat baik kepada tetangga, menghormati tamu dan bersilatuhrahmi.

Rumah seorang muslim adalah rumah yang akan menghormati tamunya. Bertamu ke rumah seseorang tidak dibenarkan kecuali atas kesepakatan keluarga yang akan kita kunjungi, karena beban menghormati tamu adalah menjadi beban semua anggota keluarga. Maka syarat bertamu adalah ridhanya mereka menerima kita sebagai tamu. Diantara adab islami dalam bertamu adalah tidak boleh memberatkan orang yang kita kunjungi agar dia menjamu kita sebagai tamu, karena hal demikian adalah pintu menuju kebakhilan. Jika menghormati tamu selalu dikaitkan dengan menjamu, mungkin ikhwan dan orang yang kita kunjungi tidak akan mampu membiayainya Seorang muslim harus senantiassa menyiapkan dirinya, rumahnya dan keluarganya untuk menerima tamu dan menghormatinya. Dan para tamu harus memahami kemampuan orang yang dikunjunginya dalam menghormati tamunya. Kalau seandainya ada sesuatu yang 
memberatkan, atau melelahkan mereka dengan kedatangannya maka dia harus mengerti dan segera berpamitan dengan cara yang sebijaksana mungkin. Hak silaturahmi itu sendiri diantara keluarga dan kerabat dengan saling menghormati, saling memberi hadiah, dan saling berkirim surat. Juga tidak lupa menyambut dengan sambutan yang baik dan penuh rasa hormat.

Adapun tetangga rumah, mereka harus merasakan damai dengan kehadiran rumah islami ini, mendapatkan perhatian yang penuh dan menyukai mereka. Rumah lslami harus dapat mencegah hal-hal yang menyakitkan mereka, dan mengetahui hak-hak mereka. Diantara hak yang harus ditunaikan oleh anggota keluarga rumah lslami terhadap tetanganya ialah memenuhi hak-hak peristiwa tertentu (huququl munasabah), baik peristiwa kegembiraan atau kesedihan. Diantara hal penting yang harus diperhatikan dalam menjaga keharmonisan hubungan dengan tetangga adalah menjaga anak-anak jangan sampai berkelahi dengan anak tetangga. Bila terjadi perkelahian maka anak tetanggalah yang harus dianggap sebagai pihak yang benar.

\section{Menjaga adab keluar masuk rumah}

Hal pertama yang harus diperhatikan oleh seorang muslim dan muslimah dalam keluar masuk rumah adalah sunnah-sunnah yang berkaitan dengan masalah tersebut, seperti do'a, kaki mana yang mesti didahulukan, dan memberi salam kepada keluarga. Diantara sunnah yang ada ialah mendahulukan kaki kiri apabila keluar. Memberi salam kepada keluarga, baik ketika masuk atau keluar rumah. Sebelum keluar rumah hendaklah menentukan niat, arah tujuan dan mengoreksi diri, serta memeriksa barang bawaannya. Isteri pun hendaknya membantu memeriksa bawaan suaminya..

Kaum wanita, apabila hendak keluar rumah hendaklah memperhatikan hal-hal berikut tidak tercium bau parfum, merapikan 
hijab dan jilbabnya sampai tidak terlihat auratnya karena tertiup angin atau salah pakai. Ada sebagian wanita yang biasa berjalan menggunakan sepatu sampai terdengar oleh orang lain dan mengundang perhatian orang untuk melihatnya. Perilaku ini bertentangan dengan adab lslami.

\section{Metode}

Pendampingan di rumah susun ini menggunakan pendekatan (ABCD) Asset Based Community Development, yakni memanfaatkan aset dan potensi yang ada disekitar dan dimiliki oleh komunitas penghuni rumah susun. Dalam metode ABCD ini terdapat lima langkah dalam melakukan pendampingan diantaranya. ${ }^{14}$

1. Discovery (Menemukan)

Pendamping melakukan wawancara kepada penghuni rumah susun untuk mengetahui aset dan potensi yang ada. Wawancara ini bersifat cerita antara penghuni rumah susun dengan pendamping sehingga yang banyak bercerita adalah penghuni rumah susun.

2. Dream (Impian)

Setelah melakukan wawancara dengan penghuni rumah susun, pendamping mulai mengetahui keinginan atau impian maka selanjutnya yaitu merancang sebuah kegiatan untuk memenuhi impian penghuni rumah susun.

3. Design (Merancang)

Proses merencanakan ini merupakan proses cara mengetahui asetaset yang ada pada penghuni rumah susun. Aset yang terlihat di wilayah rumah susun yakni tiga kelurahan di kota Pasuruan. Aset ini

14 Christopher Dureau, Pembaru dan kekuatan lokal untuk pembangunan, Australian Community Development and Civil Society Strengthening Scheme (ACCESS) Tahap II, (Agustus 2013),hal.96-97

Pendidikan Perilaku Religius Penghuni Rumah Susun Kota Pasuruan Dalam Menciptakan Baiti Jannati 
dimanfaatkan untuk memenuhi impian masyarakat penghuni rumah susun kota Pasuruan.

4. Define (Menentukan)

Kelompok pemimpin bersama pendamping menentukan topik positif dengan cara membentuk focus group discussion (FGD).

5. Destiny (Lakukan)

Serangkaian ide gagasan yang inovatif tentang apa yang terjadi di rumah susun secara organisasi dilakukan dengan kesepakatan untuk mewujudkan impian masyarakat penghuni susun agar berubah menjadi masyarakat rumah susun yang religius.

\section{Hasil dan Diskusi}

Beberapa prioritas terpenting dalam konteks prilaku religius yang bisa dilaksanakan oleh penghuni rumah susun antara lain penghuni rumah susun di setiap tempat harus melakukan peningkatan prilaku religius Islami yaitu mampu beribadah seperti sholat berjamaah, berjam'iyah, mendidik anak, menyekolahkan dan mengajikan anak, bekerja dengan giat dan halal serta bisa bermasyarakat deng harmonis, rukun dan Islami. Hal tersebut bisa dilakukan dengan cara antara lain:

1. Memperkuat idiologisasi keIslaman ahlus sunnah wal jamaah.

2. Penguatan kelembagaan TPQ dan jamiyah untuk ada dan aktif.

3. Membangun kultur tolong menolong, dan gotong royong sesama penghuni rusun.

4. Memperkuat ilmu pengetahuan dengan mengadakan pengajian serta mendatangkan ustadz yang kompeten dan sukarela memberi ilmu agama.

Pada setiap rumah susun kota Pasuruan sudah terbentuk TPQ dan aktif sehingga anak dari semua penghuni rumah susun bisa mengaji alquran dengan ustad dan ustada yang juga bertempat tinggal dirusun juga. Muridnya 
TPQ terdapat 50 murid per rusun dan anak-anak tersebut sering berjamaah khusunya maghrib dan isyak di mushollah untuk di rusun Tambaan dan di aula di rusun petahunan, hal ini juga diikuti oleh bapak-bapak dan ibu-ibu ${ }^{15}$.

Adapun setiap malam jum'atnya bagi bapak-bapak ada jamiyah yasinan, tahlilan dan dibaan bagi ibu-ibu. Mereka sangat kompak meski dilantai 5 yang paling atas, dan lelah setelah bekerja seharian mereka rela turun hadir di mushollah atau di aula. Sayangnya di rusun Petahunan belum ada mushollah meski demikian mreka semangat untuk berjam'iyah. ${ }^{16}$

Setiap sebulan sekali bagi yang tua ada pengajian dari kemenag kota Pasuruan dan pendamping mengusahakan ada pengajian tambahan sebagi santapan rohani yang akan didatangkan dari pesantren yang rela mengabdi di rusun.

Kerukunan dan keguyupan juga tampak di rusun dengan adanya posyandu. Warga rumah susn juga taat pada peratura-peraturan yang sudah ditetapkan di dalam rumah susun tersebut oleh pengurusnya dan dinas kependudukan kota Pasuruan. ${ }^{17}$

\section{Simpulan}

Pada rumah susun tersebut terbentuk keluarga-keluarga religius, sopan dan mapu berinteraksi dengan masyarakat dengan rukun aman serta melestarikan jamaah solat, kajian Islam, jamiyah tahlil, dibaan serta Taman Pendidikan al-Qur'an (TPQ) bagi anak-anak. Dengan lingkungan dan kegiatan solidaritas keagamaan penghuni rumah susun serta terdapatnya lembaga TPQ tersebut secara otomatis di rumah susun terciptalah suasana komunitas yang relgius dan bermoral sehingga rumah susun mempunyai suasana seperti surga yakni baiti jannati.

\footnotetext{
${ }^{15}$ Hasil observasi sekaligus wawancara dengan ustad Taufiq pengajar TPQ Tambakan.

${ }^{16}$ Hasil wawancara bu Hanifah istri ketua RW 5 rusun tambak.

${ }^{17}$ Hasil wawancara dengan ibu fatimah Istri RT 3 Rusun Randusari.
} 


\section{Daftar Referensi}

Kusmayana, Ali. 2009. Merencanakan, Merancang dan Membangun Rumah Tinggal Islami, diakses dari http://mejagambar.wordpress.com/ pada tanggal 29 April 2011.

Nunik Junara dan Yulia Eka Putrie. 2009. Rumah Ramah Lingkungan.UIN Press. Malang.

Omer, Spahic. 2004. Islamic Built Environtment. Malaysia.

Sa'id, Syaikh. 2002. Tatanan Rumah Islami. Robbani Press: Bandung. 